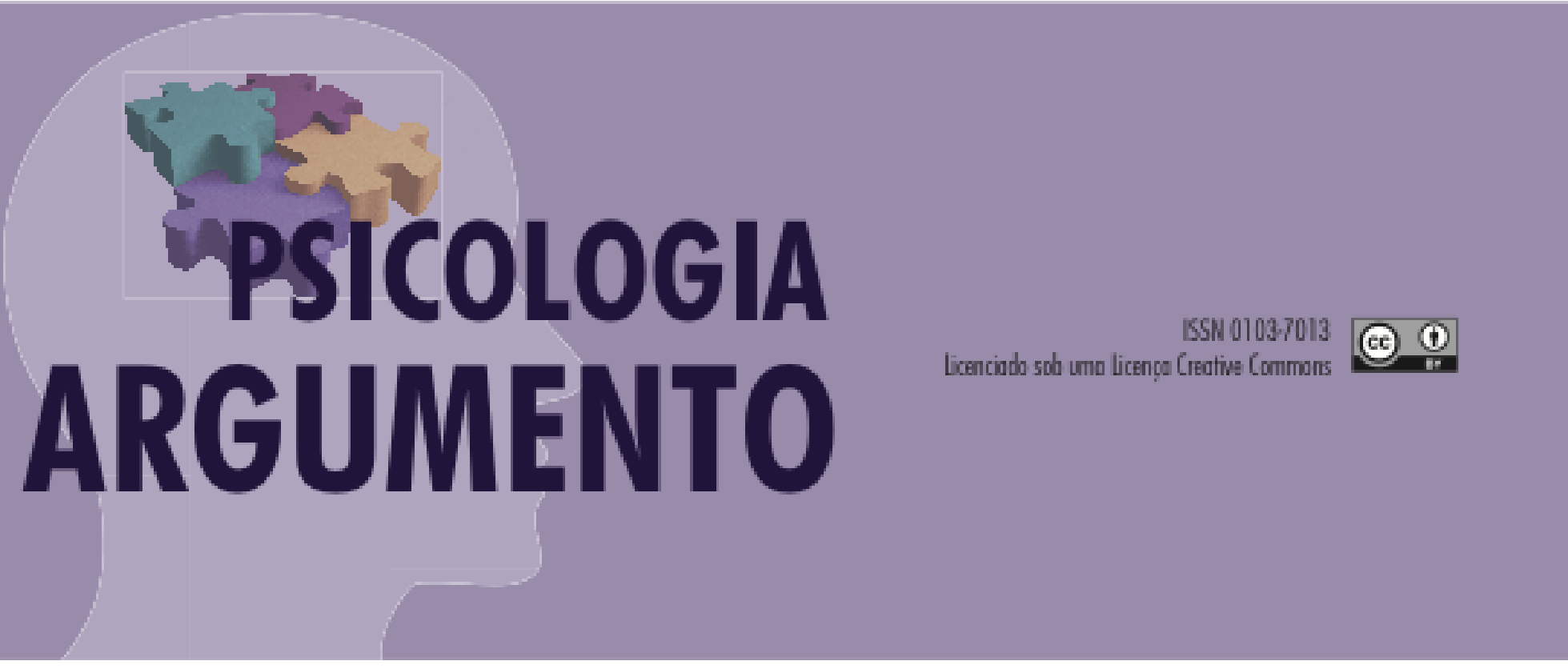

doi 10.7213/psicol.argum.33.082.AO01

\title{
Convivência familiar em três cenários: acolhimento institucional, famílias recasadas e violência doméstica
}

Right to family life in three sceneries: shelter, stepfamilies and domestic violence

Laura Cristina Eiras Coelho Soares [a], Fernanda Hermínia Oliveira Souza [b], Fernanda Simplício Cardoso [c]

[a] Professora Adjunta de Psicologia Social do Departamento de Psicologia da Faculdade de Filosofia e Ciências Humanas da Universidade Federal de Minas Gerais- UFMG e do Programa de Pós-Graduação em Psicologia da UFMG. Doutora e Mestre em Psicologia Social pela Universidade do Estado do Rio de Janeiro- UERJ. Pósgraduada em Psicologia Jurídica- UERJ. Belo Horizonte - Minas Gerais - Brasil. laurasoarespsi@yahoo.com.br

[b] Doutoranda do Programa de Pós-Graduação em Psicologia Social da Universidade do Estado do Rio De Janeiro UERJ. Pós-graduada em Psicologia Jurídica - UERJ. Aracaju- Sergipe - Brasil. herminia.fernanda@gmail.com

[c] Professora Assistente IV do Departamento de Psicologia da Pontifícia Universidade Católica de Minas GeraisPUC Minas. Doutoranda em Psicologia Social pela Universidade do Estado do Rio de Janeiro- UERJ. Psicóloga Judicial do Tribunal de Justiça de Minas Gerais - TJMG. Especialista em Psicologia Jurídica pelo Conselho Federal de Psicologia - CFP. Belo Horizonte - Minas Gerais - Brasil. fernandacsimplicio@gmail.com 


\title{
Resumo
}

O presente artigo tem como objetivo discutir a convivência familiar de crianças e adolescentes em três campos da psicologia jurídica, a saber: acolhimento institucional, recasamento e violência doméstica. No primeiro momento examinou-se a convivência familiar no acolhimento institucional com base em dados de três relatórios de pesquisas nacionais que retrataram o funcionamento das instituições de acolhimento no Brasil, a partir dos anos 2000. A segunda temática refere-se à investigação sobre as atribuições de padrastos e madrastas no trato com seus enteados, com destaque no estabelecimento da convivência familiar no recasamento após a separação conjugal. Por fim, foi problematizado o campo de intervenção da Lei 11.340/06, conhecida como Lei Maria da Penha, quanto aos seus efeitos cíveis decorrentes da aplicação das medidas protetivas de urgência, quando estas interferem na convivência familiar dos filhos com o pai acusado de agressão contra a mulher. Tais estudos baseiam-se em pesquisas sobre as novas concepções jurídicas, legais e sociais de família, de conjugalidade, de parentalidade, de parentesco e de filiação. Conclui-se que a convivência familiar constitui-se como um vasto campo de pesquisa, podendo apresentar diversas configurações e aproximações teóricas. Desta forma, promovê-la pressupõe a compreensão dos diferentes cenários que a compõem na contemporaneidade. [P]

Palavras-chave: Família; abrigo; violência; psicologia social..

\begin{abstract}
This article aims to discuss the right of children and adolescents to live in a family environment in three fields of legal psychology: shelter, remarriage and domestic violence. At first it was analyzed the right of institutionalized children and adolescents to live in a family based on data from three national surveys reports that portrayed the functioning of shelters in Brazil, since the years 2000. The second theme concerns the investigation of the roles of stepparents with their stepchildren, especially in the establishment of family life on remarriage after divorce. Finally, it was questioned the intervention field of Law 11.340 / 06, known as Maria da Penha Law, as its civil effects arising from the application of urgent protective measures when they interfere with the family life of the children with their father, who was charged with assault against his wife. Such studies are based on surveys of new legal and social concepts about family, conjugality, parenthood, kinship and affiliation. It is concluded that the right to live in a family is constituted as a vast field of research and may have various configurations and theoretical approaches. Therefore to promote it presupposes an understanding of the different scenarios that compose contemporary era. [K]
\end{abstract}

Keywords: Family; shelter; violence; social psychology.

\section{Introdução}

O direito à convivência familiar está previsto na Constituição da República Federativa do Brasil de 1988 (Brasil, 1988), ao determinar em seu artigo 227 que é dever da família, da sociedade e do Estado assegurar à criança, ao adolescente e ao jovem, com absoluta prioridade, dentre outros direitos, o de conviver junto a sua família. Em 1990, com a promulgação do Estatuto da Criança e do Adolescente (ECA), em consonância com a Constituição Federal e da Convenção Internacional dos Direitos da Criança (1989), estabelece no artigo 19, destinado ao direito à convivência familiar, que: "toda criança ou adolescente tem direito a ser criado no seio da sua família e, excepcionalmente, em família substituta, assegurada a convivência familiar e comunitária (...).”

Em 2006, foi publicado o Plano Nacional de Promoção, Proteção e Defesa do Direito de Crianças e Adolescentes à Convivência Familiar e Comunitária (2006). A relevância da convivência familiar, já apresentada no ECA (1990) e na Convenção Internacional dos Direitos da Criança (1989), é ressaltada no Plano (2006), que entende a família como um espaço de proteção e cuidado. Diante da importância atribuída pela legislação brasileira à convivência familiar discute-se, nesse texto, como este conceito relaciona-se com outras temáticas que envolvem as questões familiares em três contextos: no acolhimento institucional, no recasamento e nas situações de violência doméstica. 
Assim, as três investigações entrelaçam-se de modo a construir um cenário no qual essa questão se apresenta em diferentes perspectivas.

No campo do acolhimento institucional, o caráter provisório e excepcional dessa medida protetiva mantém relação com o direito à convivência familiar, uma vez que o artigo 19 do ECA (1990) determina que "Toda criança ou adolescente tem direito a ser criado e educado no seio da sua família e, excepcionalmente, em família substituta, assegurada a convivência familiar e comunitária, em ambiente livre da presença de pessoas dependentes de substâncias entorpecentes." Desse modo, o trabalho de reinserção familiar, tanto na família de origem quanto em família substituta é um direito que deve ser promovido não só pela Rede de Proteção à Infância e a Adolescência, mas também pelas instituições de acolhimento. Entretanto, é preciso estar atento que esta modalidade de atendimento, ao passo que visa à proteção produz um rompimento, pois o ingresso no ambiente institucional interrompe, ainda que temporariamente, a convivência junto à família e à comunidade. A partir desta realidade, buscou-se apresentar um panorama do acolhimento institucional, no Brasil, com foco na convivência familiar por meio da análise de três relatórios nacionais (Silva, 2004; Fundação Oswaldo Cruz [Fiocruz] \& Ministério do Desenvolvimento Social [MDS], 2010; Conselho Nacional do Ministério Público [CNMP], 2013) sobre a execução da medida de acolhimento.

O debate a respeito da convivência familiar no cenário do recasamento apresentase a partir de uma investigação (Soares, 2013) a respeito das atribuições de padrastos e madrastas no trato com seus enteados. Como percurso metodológico foram realizadas entrevistas individuais semi-estruturadas com seis padrastos e seis madrastas que conviviam em relacionamentos heterossexuais, de classe média, integrantes de famílias diferentes e residentes no Estado do Rio de Janeiro. As informações coletadas foram tratadas pela análise de conteúdo e a pesquisa foi aprovada pelo Comitê de Ética da Universidade. De acordo com os entrevistados, diversos fatores influenciam na construção desse lugar de padrasto/madrasta. Para fins de elaboração do presente artigo optou-se por destacar os dados obtidos que se referiam ao estabelecimento do convívio familiar no que tange aos seguintes aspectos: a coabitação ou não com o enteado; a faixa etária e o gênero dos enteados e a mediação realizada pelo pai/mãe dos enteados.

No contexto da violência doméstica e familiar contra a mulher, problematizou-se os efeitos cíveis decorrentes da aplicação das medidas protetivas de urgência, previstas na Lei 11.340/06, conhecida como Lei Maria da Penha (Brasil, 2006). A partir de revisão bibliográfica realizada acerca da temática no Brasil, buscou-se demonstrar como o fenômeno da violência doméstica e familiar contra mulher pode sobrepor aos interesses dos filhos no contexto do divórcio, supondo que questões decorrentes da conjugalidade podem ter implicações na convivência familiar dos filhos com o pai autor de agressão.

\section{A convivência familiar no acolhimento institucional}

De acordo com informações do Cadastro Nacional de Crianças e Adolescentes Acolhidos, do Conselho Nacional de Justiça, em 2011, 36.551 crianças e adolescentes encontravam-se em instituições de acolhimento. Esse número sobe para $37.240 \mathrm{em} 2012 \mathrm{e}$ para 43.585 no ano seguinte. Em 2014 existiam 45.237 crianças e adolescentes acolhidos. Em outubro de 2014, o CNJ divulgou em sua página virtual que "cerca de 3,5 mil crianças e adolescentes acolhidos foram reintegrados à família nos primeiros seis meses do ano." Destes, 2.225 voltaram a morar com a família natural e 1.308 foram viver com a família 
extensa (Freire, 2014). Como pode ser observado, o número de reintegrações informadas pelo CNJ corresponde a menos de $8 \%$ do montante de acolhidos. Diante disso, se mais de 40 mil crianças e adolescentes brasileiros encontravam-se em instituições de acolhimento torna-se relevante investigar a convivência familiar de crianças e adolescentes no contexto de acolhimento.

Para tanto, serão retomados dados de três relatórios de pesquisa nacionais que retrataram o funcionamento do acolhimento institucional no Brasil, a partir dos anos 2000, analisando de forma detida as informações dispostas sobre a convivência familiar. Assim, será examinado o livro - relatório "O direito à convivência familiar e comunitária: os abrigos para crianças e adolescentes no Brasil", coordenado por Enid Costa Silva e publicado, em 2004, pelo Instituto de Pesquisa Econômica e Aplicada [IPEA], em parceria com o Conselho Nacional dos Direitos da Criança e do Adolescente [CONANDA]. Em seguida, o "Levantamento nacional das crianças e adolescentes em serviços de acolhimento", elaborado, em 2010, pelo Ministério do Desenvolvimento Social e Combate à Fome em parecia com a Fundação Oswaldo Cruz (Fiocruz \& MDS, 2010). E, por fim, o material produzido, em 2013, pelo Conselho Nacional do Ministério Público intitulado "Um olhar mais atento aos serviços de acolhimento de crianças e adolescentes no país" (CNMP, 2013).

Na pesquisa realizada pelo Instituto de Pesquisa Econômica e Aplicada, em 2004, foram analisados dados de 626 unidades voltadas ao atendimento infanto-juvenil, que contavam à época com 19.373 crianças e adolescentes acolhidos. No tocante às informações sobre o que levou ao acolhimento, no relatório (Silva, 2004) há esclarecimentos de que não existe uma única razão para ingresso na unidade, pois os motivos são, normalmente, codeterminantes. As razões alegadas para aplicação da medida protetiva de acolhimento institucional, encontradas naquela investigação, foram: carência de recursos materiais da família $(24,1 \%)$, abandono pelos pais ou responsáveis $(18,8 \%)$, violência doméstica $(11,6 \%)$, dependência química de pais ou responsáveis $(11,3 \%)$, vivência de rua $(7 \%)$, orfandade $(5,2 \%)$, prisão dos pais ou responsáveis $(3,5 \%)$, abuso sexual praticado pelos pais ou responsáveis (3\%), ausências de pais ou responsáveis por doença $(2,9 \%)$, doença mental de pais ou responsáveis portadores $(2,2 \%)$. Segundo Silva (2004), a pobreza familiar foi responsável pelo ingresso de mais da metade (52\%) de crianças e adolescentes nas instituições. É preciso ressaltar que a autora utiliza em seu texto os termos carência de recursos e pobreza como sinônimos.

No que se refere à análise do vínculo familiar e do tempo de permanência na instituição, está descrito que $87 \%$ das crianças e adolescentes acolhidos possuíam família e, 58,2\% mantinham vínculos com ela. Importante destacar que naquele material, a manutenção do contato da criança com os familiares está associada às visitas que estes últimos realizavam a instituição. Foi constatado que 22,7\% não mantinham vínculo familiar constante, somente $5,8 \%$ dos abrigados estavam impedidos judicialmente de contato com os familiares e, 11,3\% foram incluídos nas categorias "sem família" ou "família desconhecida."

Silva (2004) investigou, ainda, junto aos dirigentes das unidades de acolhimento, quais seriam as principais dificuldades para a reinserção familiar e comunitária: 35,5\% das respostas foram relacionadas às condições socioeconômicas das famílias, 17,6\% correspondiam à fragilidade, perda ou ausência de vinculação familiar, 10,8\% à inexistências de políticas públicas e de ações institucionais de apoio à reestruturação 
familiar, 5,7\% ao uso de drogas, e 5,1\% à violência doméstica. A autora concluiu que a vulnerabilidade social das famílias aliada a carência de políticas sociais leva ao acolhimento de crianças e adolescentes.

Com o intuito de avaliar as medidas empreendidas para a manutenção dos vínculos familiares foram consideradas dois grupos de ações: incentivo a convivência com a família de origem e o não desmembramento de grupos de irmãos (Silva, 2004). Em relação ao primeiro grupo, os resultados encontrados, à época, indicam que 79,8\% das instituições mantinham informações sistematizadas sobre as famílias dos acolhidos como: dados sociodemográficos, visitas, irmãos acolhidos e registro de acompanhamento psicossocial. Mais da metade dos estabelecimentos investigados $(65,9 \%)$ promovia visitas das crianças e adolescentes à casa de seus familiares, e $41,4 \%$ permitia visita livre na unidade. Em referência a não separação de irmãos, 63,8\% dos estabelecimentos analisados (Silva, 2004) afirmou priorizar a manutenção ou recomposição do grupo fraterno. Interessante notar que a existência de informações sobre as famílias de crianças e adolescentes acolhidos foi considerada item referente ao estímulo à convivência familiar, contudo, não existem detalhes sobre o modo como era realizado o acompanhamento psicossocial.

As iniciativas, descritas por Silva (2004), que tinham como objetivo reestruturar as famílias dos acolhidos foram: visitas domiciliares (78,1\%), acompanhamento social $(65,5 \%)$, reuniões ou grupos de discussão e de apoio para os familiares $(34,5 \%)$ e, inserção em programas oficiais ou comunitários de auxílio/proteção à família $(31,6 \%)$. Vale ressaltar que essas ações não eram realizadas ao mesmo tempo, somente 14,1\% desenvolviam todas as tarefas conjuntamente. Não se encontra descrito, no relatório, como essas atividades eram realizadas. $\mathrm{O}$ que essas unidades compreendem por acompanhamento social? Que trabalhos são propostos na visita domiciliar? Detalhes sobre essas questões não foram contemplados. Por outro lado, o levantamento de 2004 apresenta dados relativos à integração em família substituta por meio de guarda, tutela ou adoção, assim como a existência de programas de apadrinhamento afetivo. Tais programas foram descritos, por Silva (2004), como "alternativa de referência familiar para crianças e adolescentes abrigados" (p.230) utilizadas por $81,5 \%$ das instituições pesquisadas.

Em 2010, a Fundação Oswaldo Cruz em parceria com o Ministério de Desenvolvimento Social, divulgou que naquele ano existiam 2.624 serviços de acolhimento institucional em 1.157 municípios brasileiros e, 36.929 crianças e adolescentes acolhidos. De acordo como estudo ora analisado, os principais motivos alegados para o ingresso na unidade foram: abandono pelos pais ou responsáveis (19\%), pais ou responsáveis dependentes químicos/alcoolistas $(20,1 \%)$ e, negligência na família $(37,6 \%)$. Os dados pertinentes à reinserção familiar indicaram que $61 \%$ das crianças e adolescentes possuíam família e vínculo com a mesma. Em apenas $2,4 \%$ dos casos a família estava desaparecida/ não localizada; $23,2 \%$ possuíam família, mas não existia vínculo; $1,4 \%$ tinham família e não havia informação sobre o vínculo; $8,6 \%$ tinham impedimento judicial de contato com a família; $1,1 \%$ sem família e, 2,3\% não sabiam. A maioria dos acolhidos $(59,4 \%)$ recebia visitas na instituição, 40,1\% não recebiam e $0,5 \%$ não sabiam informar. Os principais motivos alegados para o desligamento da unidade foram: retorno para família de origem $(93,2 \%)$, evasão $(32,2 \%)$, adoção nacional $(55,8 \%)$, adoção internacional $(12,7 \%)$, mudança para outro serviço de acolhimento $(29,4 \%)$, falecimento $(3,6 \%)$, maioridade $(33,8 \%)$ e outro $(5,1 \%)$ (Fiocruz \& MDS, 2010). 
Em 2013, o Conselho Nacional do Ministério Público lançou um relatório com dados relativos aos serviços de acolhimento institucional e familiar no Brasil (CNMP, 2013). Segundo a pesquisa, a inspeção foi realizada em $86,1 \%$ das entidades de acolhimento de todo o Brasil, nas modalidades: acolhimento institucional, casa- lar e casa de passagem. Foram investigadas 2.247 entidades de acolhimento institucional e pôde-se apurar que os principais motivos para o ingresso em abrigo ou casa- lar foram: negligência dos pais e/ou responsável (mais de 80\%); dependência química/alcoolismo dos pais e/ou responsável; (mais de 80\%); abandono dos pais e/ou responsável (em torno de 77\%); violência doméstica (próximo a 60\%), e abuso sexual praticado pelos pais e/ou responsável (em torno de 45\%). Vale ressaltar que mais de um motivo foi citado como causa para o acolhimento, o que explica o somatório dos índices ultrapassar 100\%.

No item "visitação aos acolhidos", foi constatado que em mais de $75 \%$ das entidades de acolhimento existiam crianças e adolescentes que não recebiam visitas dos pais há dois meses ou mais. Todavia, os motivos para a inexistência de visitas não foram informados. As taxas de reintegração familiar descritas no Relatório do Conselho Nacional do Ministério Público (2013) evidenciaram que um número expressivo de crianças e adolescentes retornou para suas famílias. Indica, contudo, que malgrado o alto percentual de reintegração, não houve redução no número de acolhidos, o que aponta para a necessidade de realização de outros estudos.

Nos levantamentos examinados neste artigo, o foco das investigações foi a descrição dos serviços e das crianças e adolescentes acolhidos. São encontradas informações sobre: perfil das entidades, tempo de funcionamento institucional, capacidade total e ocupação atual, guia de acolhimento, Plano Individual de Atendimento (PIA), capacitação dos profissionais, apadrinhamento afetivo, ambiente físico, tipo de financiamento, faixa etária dos acolhidos, causas para o acolhimento, visitação, tempo de permanência na instituição, projeto político pedagógico e situação legal de crianças e adolescentes (Silva, 2004; Fiocruz \& MDS, 2010; CNMP, 2013). As famílias, quando citadas, apareciam como motivadoras da medida e responsáveis pelo desligamento institucional. Na pesquisa coordenada por Silva, em 2004, em nenhum capítulo, das mais de quatrocentas páginas que compõem o material, constam informações sobre as famílias dos acolhidos.

Se a convivência familiar implica na relação entre crianças e adolescentes e suas famílias, estas últimas deveriam estar presentes no processo de acolhimento e desligamento institucional. Salvo situações graves, para as quais foi determinado judicialmente proibição de visitação, não há impedimento para a manutenção da relação entre pais e filhos. Desse modo, é preciso examinar que sentidos têm sido atribuídos à convivência familiar no contexto de acolhimento, uma vez que se pôde observar escassez de informações, nas pesquisas apresentadas, sobre as famílias de crianças e adolescentes acolhidos e do trabalho com elas realizado.

\section{A convivência familiar no recasamento}

No que concerne ao tema da convivência familiar no recasamento após separação conjugal serão apresentadas informações de pesquisa realizada com padrastos e madrastas sobre suas atribuições no cuidado com seus enteados (Soares, 2013). Diante dos múltiplos dados levantados elegeu-se, para apresentar neste artigo, dois eixos visando auxiliar na compreensão da construção do lugar de padrasto/madrasta no convívio com os enteados. O 
primeiro refere-se à influência da frequência desse contato, que pode ser cotidiana ou intermitente, na edificação dessa relação. O segundo eixo, trata da posição adotada pelo pai/mãe recasado na intermediação desse relacionamento, visando a facilitar essa convivência familiar.

No que tange ao primeiro eixo, o padrasto/madrasta pode ter encontros mais esporádicos com essa criança, tais como os padrastos/madrastas "intermitentes" (Fine, 2001), o que permite uma prática de maior tolerância na interação. Nesse cenário, a convivência familiar sofre influência direta do modelo de guarda de filhos adotado no pósdivórcio. Sobre essa questão, quatro madrastas entrevistadas - Yasmin , Rosa, Ana e Patrícia - vivenciaram períodos de coabitação com os enteados e todos os seis padrastos compartilhavam a residência com o enteado no momento da entrevista.

Contudo, a entrevistada Neusa, vivenciou somente a condição de "madrasta intermitente" (Fine, 2001) e ao ser indagada sobre a frequência das idas dos enteados à casa do pai, respondeu: "Vão uma vez por mês, uma vez a cada dois meses (...) Embora eu fique enlouquecida quando eles estão lá, somos só nós dois, então muda toda a rotina, bagunça tudo, mas é gostoso." Nesse sentido, pode ser observada a mudança provocada na rotina, que em decorrência do pai não ser o guardião, aproxima-se de um cotidiano de casal de primeira união, sendo modificado somente nos períodos de visitação dos filhos da união anterior. Na construção do vínculo entre padrasto/madrasta e enteado pode surgir a vontade de querer agradar ao filho do cônjuge. Essa conduta foi citada pela madrasta Patrícia: "Logo quando eu os conheci, eu fazia tudo para agradá-los, porque assim eu agradava meu marido, os meus filhos tinham ciúmes."

Esse comportamento inicial pode gerar decepção por parte dos enteados, que identificam uma mudança no modo de agir das madrastas ao longo do tempo. As madrastas Yasmin e Patrícia coabitaram com seus enteados em algum momento da trajetória conjugal e modificaram sua maneira de lidar no decorrer dos anos. Talvez a permanência dessa artificialidade na conduta seja possível apenas para aqueles que têm seu contato intermitente com os enteados, como a situação vivenciada por Neusa: "Quando vão lá para casa tento agradar, fazer o que gostam." Com o contato esporádico torna-se viável e, talvez, esperado que a madrasta ou o padrasto de final de semana fique responsável pelo lazer e pela oferta de agrados aos enteados.

A maneira como o padrasto/madrasta é integrado à família também sofre modificações com a convivência. Essa variável pode ser um facilitador para o relacionamento permitindo uma aproximação e estreitamento do laço, como também pode funcionar como fonte de conflito e provocar distanciamento. Do mesmo modo que os padrastos/madrastas "intermitentes" (Fine, 2001) podem usufruir da distância para promover encontros esporádicos divertidos, também podem justificar sua falta de vínculo com os enteados em função da raridade dos encontros.

A convivência aparece nos relatos como o fator mais relevante para o estreitamento do laço com o enteado, pois a relação é construída no cotidiano com o passar do tempo compartilhado. O transcorrer do tempo também pode desfazer um distanciamento inicial, marcado por receio, preconceitos e ciúmes, permitindo que uma relação de troca e identificação seja estabelecida. O padrasto Guilherme relata a mudança pela qual a enteada passou: "No início ela tinha ciúmes, por que tinha um cara roubando a atenção da mãe dela. Depois viu que não estava roubando, estava agregando à família." 
No seguinte trecho, da entrevista de João, pode ser notada a superação do preconceito: "No início olha que é um filho que não é meu, mas hoje ele fala como eu falo, usa o vocabulário, e hoje o torna parte minha, tem um pouco de mim, mesmo que não fisicamente." A partir desse relato pode-se refletir a respeito dos laços estabelecidos entre padrasto/madrasta e enteado, que podem apontar para a possibilidade de transmissão de valores e hábitos.

$\mathrm{O}$ aspecto gradativo dessa construção do vínculo é, por vezes, esquecido no recasamento. $\mathrm{O}$ pai/mãe recasado pode estar esperando uma afinidade imediata entre seu cônjuge e seu filho, conforme identificado por Claro, Kirby e Muller (1993) e denominado de mito do amor ou ajuste instantâneo. Esse mito, aplicado às famílias recasadas, refere-se à expectativa de que rapidamente irá se estabelecer uma proximidade afetiva entre o filho e o padrasto/madrasta, sem considerar o fato de que as relações exigem tempo para serem construídas. Como ilustração, segue a fala da madrasta Yasmin que parece centrar-se em uma concepção de família pautada no afeto irrestrito e imediato: "eu sempre tive em mente o seguinte: você casa com a pessoa, você tem a obrigação de amar as pessoas da família? Tem.”

Já a madrasta Neusa adiciona, além da questão do estabelecimento gradual, também a ideia de que o fato de gostar de crianças facilitaria seu contato com os enteados: "eu tentei ser natural, não forçar essa aproximação, eu gosto muito de crianças, o que facilitou esse encontro e facilita a convivência." No entanto, o lugar ocupado pela madrasta é diferente de uma pessoa externa sem ligação com a família e, portanto, pesquisas (Soares, 2015; Church, 2005) identificaram que não há essa correlação entre lidar bem com crianças e ter bom trato com os enteados. A presença da madrasta pode provocar ciúmes e conflito de lealdade, ou seja, um espaço de disputa que não ocorre em outras situações sociais.

Neste sentido, a mediação do pai/mãe recasado pode ser fundamental para o estabelecimento dessa convivência familiar e para a construção do vínculo entre padrasto/madrasta e enteado. Essa temática refere-se ao segundo eixo a ser abordado na pesquisa a respeito de famílias recasadas. A importância dessa atuação como mediador pode ser evidenciada na fala da madrasta Rosa: "O meu marido ajudou nisso, a participação dele foi importante, [a relação] foi construída aos poucos. Ele aproximava, ele era o meio de campo entre eu e a [minha enteada]." Esse papel do pai e mãe recasado também apareceu no relato do padrasto João: “O [meu enteado] tem total consciência de que eu sou parte integrante da educação dele, de tudo que envolve as coisas da vida dele, a [minha esposa] ajudou muito com isso."

Outros pesquisadores (Lobo, 2009; Atalaia, 2010) também observaram a relevância da mediação do cônjuge para o estabelecimento da relação padrasto/madrasta e enteado. Por vezes, a mãe delimita o campo de atuação para o padrasto, definindo suas atribuições. Se anteriormente, observou-se essa mediação como um processo de facilitação, nesse momento destaca-se essa posição do pai/mãe recasado na restrição das atribuições desempenhadas pelo padrasto/madrasta.

A importância dessa mediação não ocorre somente na relação entre padrasto/madrasta e enteado, mas também pode ser necessária entre pais e filhos. Desta forma, o padrasto/madrasta pode auxiliar nessa interlocução, atuando como um terceiro que negocia com o pai/mãe algumas demandas do enteado. Esse auxílio do padrasto/madrasta pode ser um fator responsável pela construção de uma cumplicidade 
com o enteado, que percebe no padrasto/madrasta uma pessoa que pode ajudá-lo no trato com a mãe/pai. O entrevistado Heitor se percebe nesse lugar: "A mãe era um sargento, eu acho até que eu atrapalhei, fazia todas as vontades dela, então comigo ela conseguia tudo, então vinha me procurar para ter acesso à mãe."

O entrevistado Lorenzo esclarece que a edificação do seu elo com o enteado foi feita de maneira independente da relação com a genitora. Isso permitiu que, mesmo durante um breve período em que esteve separado dela, mantivesse contato com o enteado. Em outros casos, observa-se que o lugar do padrasto/madrasta é marcado pela relação estabelecida com o cônjuge, ou seja, para o enteado a presença do padrasto/madrasta está fortemente vinculada ao pai/mãe recasado. No entanto, mesmo nessas famílias, o padrasto/madrasta pode se posicionar como uma referência para o enteado, como uma pessoa que pode lhe oferecer ajuda, conforme evidenciado na fala da madrasta Patrícia: "Sou uma pessoa que está com seu pai e estou aqui para ajudar no que você precisar. Ele sempre demonstrou amor com meus filhos como eu com os filhos dele." No mesmo sentido, o padrasto Lorenzo expressou: "Acho que ele pensa mais que tudo que eu sou constante, isso é o mais importante."

A referência não é só do padrasto em relação ao enteado, mas também pode ser o contrário, conforme se percebe na própria entrevista concedida por Lorenzo: "Ele [o enteado] é uma referência para mim (...). Eu me modifiquei muito por causa dele, ele me ensinou muita coisa." Desta forma, pode-se compreender que a construção da relação afetiva entre padrasto/madrasta e enteado envolvem, segundo os entrevistados, o tempo de convivência e a mediação realizada pelos pais/mães recasados.

\section{A convivência familiar no contexto de violência doméstica e familiar contra a mulher}

A Lei $\mathrm{n}^{\circ}$ 11.340, promulgada em 07 de agosto de 2006 - conhecida como Lei Maria da Penha (Brasil, 2006), cria mecanismos para coibir e prevenir a violência doméstica e familiar contra a mulher e dispõe sobre a criação dos Juizados Especializados de Violência Doméstica e Familiar contra a Mulher. De acordo com a referida lei, configura-se como violência doméstica e familiar contra a mulher qualquer ação ou omissão baseada no gênero (Brasil, 2006). Para o julgamento de crimes dessa natureza, a Lei Maria da Penha define que os Juizados terão competência criminal e cível, e podem apreciar questões relacionadas à guarda, visitação, partilha e alimentos. Na falta dos Juizados ou Varas Especializados, os processos serão julgados nas Varas Criminais, conforme prevê a lei ao estabelecer:

Enquanto não estruturados os Juizados de Violência Doméstica e Familiar contra a Mulher, as varas criminais acumularão as competências cível e criminal para conhecer e julgar as causas decorrentes da prática de violência doméstica e familiar contra a mulher, observadas as previsões do Título IV desta Lei, subsidiada pela legislação processual pertinente (Brasil, 2006).

Essa prerrogativa não exclui a possibilidade de as partes atendidas nas Varas Maria da Penha ou Criminais terem outro processo judicial tramitando na Vara de Família. Embora o juiz criminal tenha competência para julgar matéria cível, conforme previsto na Lei Maria da Penha, as partes podem buscar amparo nas Varas de Família para resolver questões atinentes ao divórcio. Isso porque os feitos judiciais são independentes e podem, até mesmo, gerar decisões cíveis diferentes, sobretudo, conflitantes. Por exemplo, o fato 
de o juiz criminal suspender as visitas paternas, com fundamento no inciso IV do artigo 22 da Lei 11.340/06 (Brasil, 2006), não significa que o juiz da Vara de Família determinará o afastamento do pai em relação aos filhos, mesmo porque uma das molas propulsoras do Direito de Família é a garantia da convivência familiar. Nesse caso, não são os direitos da mulher que assumem centralidade, mas a equidade entre os direitos e deveres dos pais, e o princípio do melhor interesse da criança e do adolescente quando envolvidos no litígio conjugal.

Observa-se a partir da revisão de literatura, que a política judiciária desenvolvida com fulcro na Lei 11.340/06 (Brasil, 2006) enfatiza as questões de gênero e o tratamento criminal para o fenômeno da violência doméstica e familiar. Sendo assim, as questões afetas ao interesse dos filhos, principalmente relativas ao convívio com o pai acusado de cometer à agressão contra a mulher, não são tratadas como prioridade. Batista (2008) chama a atenção para o aspecto criminalizante da referida lei, afirmando que a intervenção primordialmente punitiva por parte do Poder Judiciário pode contribuir para aumentar os níveis de controle e vigilância do Estado sobre a vida privada. Como consequência, os sistemas penais são reforçados e podem transformar os interesses da vida privada em pública.

Alguns autores, críticos à maneira simplista de se operar com a Lei Maria da Penha, alertam para a importância de se averiguarem os seus possíveis desdobramentos, tais como seus efeitos na esfera cível (Segata, 2008), as suas consequências na perspectiva da judicialização das relações conjugais (Rifiotis, 2008), a ênfase predominante na penalização exacerbada do homem e o destaque para a vítima como alvo de proteção (Batista, 2008).

Ao se manifestar sobre o alcance das medidas protetivas previstas na Lei Maria da Penha, Batista (2008) assevera:

Certamente o setor mais criativo e elogiável da lei reside nas medidas protetivas de urgência (arts. 22, 23 e 24). Ali estão desenhadas diversas providências que podem, no mínimo, assegurar níveis suportáveis no encaminhamento de solução para conflitos domésticos, até patrimoniais. O perigo estará potencialmente, aqui, num abusivo emprego penal das medidas protetivas de urgência, que estão amplamente legitimadas enquanto coerção direta. Mas a suspensão de visitas aos filhos (art. 22, inc. IV) pode ser abusivamente manejada como pena sempre que, a despeito da agressão contra a mãe, a relação do agressor com seus filhos não estiver afetada (Batista, 2008, p. 12).

$\mathrm{Na}$ esteira desse pensamento seguem outros autores como Karam (2006), ao afirmar que a suspensão ou restrição de visitas viola o direito da criança à convivência familiar. A autora faz referência ao caput do artigo 227 da Constituição Federal Brasileira (1988) (Brasil, 1988) e ao parágrafo $3^{\circ}$ do artigo $9^{\circ}$ da Convenção Internacional sobre os Direitos da Criança (1989) para firmar seu posicionamento contra a violação desse direito.

Noutro giro, observa-se que a Lei 11.340/06 tem aparecido cada vez mais nos processos judiciais que tramitam nas Varas de Família dos Tribunais de Justiça, inclusive criando impasses em relação aos direitos dos envolvidos. É quase inevitável a aplicação da medida protetiva de afastamento do homem em relação à mulher quando há denúncia de qualquer tipo de violência doméstica e familiar prevista na lei. Nestes casos, pode ocorrer de a história da violência estar circunscrita ao contexto do divórcio, sem histórico de conduta violenta praticada pelo homem em outras fases da vida conjugal. Um aspecto observado é de que a violência é muitas vezes recíproca, ou seja, praticada por ambas as 
partes, mas só o homem responde nesse lugar de criminoso. Outra característica identificada é a ausência de relatos de violência praticada contra os filhos, apesar de isso não garantir a continuidade da convivência parental.

Quando a mulher detém a guarda, as medidas protetivas podem ser usadas para justificar o afastamento dos filhos em relação ao pai, desincumbindo a mulher de qualquer implicação com o direito à convivência familiar dos menores em questão. Convém pensar nos prejuízos que podem advir de uma situação em que a mulher é atendida na delegacia e pede a medida protetiva de suspensão e restrição de visitas do companheiro aos filhos do casal e o pedido é acatado pelo juiz, sem averiguação da relação paterno filial. Supõe-se que essa realidade possa resultar, por vezes, na aplicação de medidas protetivas com base, exclusivamente, em queixas das vítimas, sem apuração dos reais motivos que justificam o pedido de afastamento do homem e seus possíveis desdobramentos na esfera familiar.

De modo geral, as ações de combate à violência contra a mulher no âmbito doméstico e familiar, coordenadas pelo Conselho Nacional de Justiça (2013) ou apoiadas por esse órgão parecem destinadas a proteção dos direitos da vítima e a penalização do agressor, pressupondo que a violência é um fenômeno dicotomizado que delimita claramente o lugar de cada um dos atores envolvidos. Nesse sentido, prevalece o que Garland (2008, p.317) chamou de "santificação das vítimas" e, como consequência sua incompatibilidade total com o agressor, fazendo com que qualquer atitude de compaixão ou invocação de direitos deste último, seja visto como insulto aos que supostamente necessitam de proteção.

Segundo autores pesquisados (Acosta \& Bronz, 2014; Andrade, 2014; Beiras \& Cantera; 2014), nos grupos com homens autores de agressão, os atendimentos realizados geralmente se restringem a indicações e obrigações impostas, partindo de uma lógica dicotômica que polariza a relação homem e mulher. Trata-se de abordagens essencialistas que não exploram o viés relacional que pode ter gerado a violência e, menos ainda, se propõem a compreender a dinâmica das subjetividades em jogo. Não atentam para as questões culturais, sociais, políticas, afetivas e emocionais envolvidas na condição de quem pratica a violência, aprofundando pouco ou nada em temas transversais que refletem o modo de posicionamento do homem em suas relações.

Nesse contexto, os efeitos cíveis decorrentes da aplicação da Lei Maria da Penha, como a suspensão de visitas aos filhos, não parece um assunto explorado por alguns grupos, mesmo porque em nossa cultura prevalece a tendência a se pensar que parentalidade não é assunto de interesse para o homem, principalmente para aquele que pratica a violência contra a mulher. Como pode ser observado são muitas questões suscitadas sobre os desdobramentos da Lei Maria da Penha, tanto para as mulheres como para os supostos agressores e os filhos destes. Há que se interrogar por que questões decorrentes da conjugalidade, como a violência doméstica contra a mulher, aparecem tão imbricadas com as expectativas depositadas no exercício da parentalidade, e quais as suas implicações na convivência familiar dos filhos com o pai autor de agressão.

\section{Considerações finais}

A convivência familiar, escolhida como eixo condutor do presente artigo, foi estudada a partir de diferentes aproximações. No campo do acolhimento institucional, os levantamentos nacionais apresentados (Silva, 2004; Fiocruz \& MDS, 2010; CNMP, 2013) 
fornecem extenso material sobre o acolhimento institucional no Brasil e seus dados podem ser úteis para a investigação dos sentidos e interpretações que a convivência familiar adquire nas práticas de acolhimento. Dentre os inúmeros tópicos abordados destacam-se: a inexistência de informações sobre as famílias de crianças e adolescentes acolhidos, a ausência de relatos sobre o processo de reintegração familiar, a recorrência dos motivos para o acolhimento que, em sua maioria, estavam relacionados às dificuldades financeiras dos pais ou responsáveis. Ainda concernente às causas para ingresso na unidade sobressaíram: negligência dos familiares, abandono e pais dependentes químicos ou alcoolistas.

No entanto, observou-se escassez de informações sobre as famílias de crianças e adolescentes acolhidos e do trabalho com elas realizado, o que pode ser compreendido como uma possível evidência da falta de articulação entre o acolhimento institucional e as famílias de crianças e adolescentes acolhidos. Tais observações provocam os seguintes questionamentos: o que estaria sendo entendido por convivência familiar? Poder-se-ia supor que a família de origem não tem sido contemplada como prioridade na promoção da convivência familiar no acolhimento institucional? De que família se fala quando é mencionado o direito à convivência familiar no acolhimento institucional?

No cenário do recasamento optou-se por apontar alguns atravessamentos presentes nesse cotidiano do convívio nessa configuração familiar e, portanto, não se trata propriamente da promoção do direito à convivência, mas do exercício diário desse direito e sua complexidade diante das mudanças que a família percorreu. No que se refere à convivência familiar nesse contexto, observou-se que a relação entre padrasto/madrasta e enteado sofre modificações com a passagem do tempo e o contato cotidiano. Desta forma, o modelo de guarda de filhos, unilateral ou compartilhada, revela-se como mais um fator que influenciará na construção desse laço.

A mediação realizada pelo pai/mãe dos enteados foi destacada como relevante para o estabelecimento do laço afetivo entre padrasto/madrasta e enteado. Dessa forma, buscou-se evidenciar as particularidades dessa configuração familiar no que tange ao exercício da convivência, apontando atravessamentos que contribuem para o surgimento e para a manutenção dos vínculos familiares, entendendo-a como um formato que deve ser considerado em suas peculiaridades.

Em relação à convivência familiar no contexto da violência contra a mulher, constatam-se, até o momento, poucos estudos ou pesquisas publicados no Brasil que abordam os possíveis impasses da Lei Maria da Penha no direito de convivência dos filhos com os pais supostamente autores de agressão (Batista, 2008; Rifiotis, 2008; Segata, 2008). Nos casos de aplicação de medida protetiva decorrente de violência conjugal supõe-se que pode ocorrer a obstrução do direito à convivência familiar dos filhos em relação ao pai acusado de agressão.

Observa-se que a Lei 11.340/06 tem aparecido cada vez mais nos processos judiciais que tramitam nas Varas de Família dos Tribunais de Justiça do país, às vezes causando impasses à convivência parental dos filhos havidos da relação conjugal. Quando há aplicação da medida protetiva de afastamento do homem em relação à mulher, e esta detém a guarda judicial dos filhos, é necessário resguardar o direito dos filhos de ter a convivência familiar preservada e garantida, conforme preceituam as leis mencionadas neste artigo. 
As diversas perspectivas desenvolvidas visaram à ampliação do entendimento sobre o conceito de convivência familiar, ocupando-se de prismas distintos a respeito desse direito, abordado em seus aspectos de promoção, de exercício e de garantia. Diante do exposto, espera-se contribuir para que a temática da Família, que possui aspecto central nas legislações brasileiras e diretrizes políticas atuais (Rizzini et al, 2007), estabeleça-se como um amplo campo de pesquisas sob um olhar crítico e reflexivo, a fim de subsidiar debates que articulem a lei, a teoria e a prática.

\section{AGRADECIMENTOS}

À Coordenação de Aperfeiçoamento de Pessoal de Nível Superior (CAPES), pela Bolsa de Doutorado Sanduíche, Proc.nº BEX 8742/11-1, concedida no ano de 2012 à primeira autora.

À Fundação de Amparo à Pesquisa do Estado do Rio de Janeiro (FAPERJ), pela Bolsa de Doutorado, Proc.n ${ }^{\circ}$ E-26/100.722/2014, concedida à segunda autora no ano de 2014 e À Coordenação de Aperfeiçoamento de Pessoal de Nível Superior (CAPES), pela Bolsa de Doutorado Sanduíche, Proc.n $n^{\circ}$ BEX 10318/14-3, concedida de abril de 2015 a março de 2016 à segunda autora.

\section{Referências}

Acosta, F. \& Bronz, A. (2014) Desafios para o trabalho com homens em situação de violência com suas parceiras íntimas. In: Blay, E.A. (Org.). Feminismos e masculinidades: novos caminhos para enfrentar a violência contra a mulher. (pp. 139148). São Paulo: Cultura Acadêmica.

Andrade, L.F. (2014). Grupos de homens e homens em grupos: novas dimensões e condições para as masculinidades. In: Blay, E.A. Feminismos e masculinidades: novos caminhos para enfrentar a violência contra a mulher. (pp.173-210). São Paulo: Cultura Acadêmica.

Atalaia, S. (2010). O lugar do padrasto no quotidiano familiar. In: Wall, K.; Aboim, S. \& Cunha, V. (coords). A Vida Familiar no Masculino: Negociando Velhas e Novas Masculinidades. (p. 397- 455). Lisboa: Editora Comissão para a Igualdade no Trabalho e no Emprego, Estudos 6.

Batista, N. (2008). E só Carolina não viu: violência doméstica e políticas criminais no Brasil.. Jornal do Conselho Regional de Psicologia, Rio de Janeiro, n. 5, p. 1-20, 2008. Recuperado em 11 fevereiro, de 2015, de http://www.crprj.org.br/publicacoes/jornal/jornal17-nilobatista.pdf.

Beiras, A \& Cantera, E. M. (2014). Feminismo pós estruturalista e masculinidade: contribuições para intervenção com homens autores de violência contra as mulheres. In: Blay, E.A. (Org.). Feminismos e masculinidades: novos caminhos para enfrentar a violência contra a mulher. (pp. 29-44) São Paulo: Cultura Acadêmica. 
Bezerra, A. (2014). Polêmica, lei prioriza vaga em escolas de Manaus a filhos de mulheres agredidas: pela lógica da Lei 395/2014, pai que espancar a mãe pode conseguir prioridade e garantir vaga aos filhos em escolas e creches da Prefeitura. Recuperado em 11 de fevereiro, de 2015, de http://new.d24am.com/noticias/amazonas/polemica-prioriza-vaga-escolas-manausfilhos-mulheres-agredidas/121013.

Constituição da República Federativa do Brasil. (1988, 5 de outubro). Recuperado 15 de abril, de 2015, de http://www.planalto.gov.br/ccivil_03/Constituicao/Constituicao.htm.

Brasil (2006). Lei no 11.340, de 7 de agosto de 2006. [Lei Maria da Penha]. Dispõe sobre mecanismos para coibir a violência doméstica e familiar contra a mulher. Diário Oficial da União. Brasília, DF. Recuperado em 12 de maio 2015, de http://www.planalto.gov.br/ccivil_03/_ato2004-2006/2006/lei/l11340.htm

Brasil (1990). Estatuto da Criança e do Adolescente. Lei no. 8.069 de 13 de julho de 1990. Dispõe sobre o Estatuto da Criança e do Adolescente e dá outras providências. $\begin{array}{lllll}\text { Recuperado em } 12 \text { maio de } & \text { 2015, }\end{array}$ http://www.planalto.gov.br/ccivil_03/leis/L8069Compilado.htm

Plano Nacional de Promoção, Proteção e Defesa do Direito de Crianças e Adolescentes à Convivência Familiar e Comunitária (2006). Secretaria Especial dos Direitos Humanos. - Brasil-DF: CONANDA.

Brasil-Unicef-Ministério da Justiça. (1989) Convenção Internacional sobre os Direitos das Crianças. Brasília, DF: Governo Federal.

Brito, C. O.; Rosa, M. E. \& Trindade, Z. A. (2014). 0 processo de reinserção familiar sob a ótica das equipes técnicas das instituições de acolhimento. Temas em Psicologia. 2 (22) p. 401-413.

Brito, L. M T. de. (1997). Pais de fim de semana - questões para uma análise jurídicopsicológica. Revista Psicologia Clínica. Rio de Janeiro: PUC-RJ. 8 (8), p.139-152.

Church, E. (2005). Uma estranha no ninho: os desafios de quem se casa com quem já tem filhos. São Paulo: Globo.

Claro, C. B.; Kirby, M. R. \& Muller, N. M (1993). Redes temáticas para eltrabajo educativo con famílias simultáneas. Revista Psykhe, 2 (1), p.43-51.

Conselho Nacional de Justiça. (2013). O Poder Judiciário na aplicação da Lei Maria da Penha. Brasília, DF. Recuperado em 28 de outubro de 2015, de http://www.cnj.jus.br/images/programas/lei-maria-dapenha/cartilha_maria_da_penha.pdf

Conselho Nacional do Ministério Público. (2013). Relatório da Infância e Juventude Resolução no 71/2011: Um olhar mais atento aos serviços de acolhimento de crianças e adolescentes no País. Recuperado em 12 de maio 2015, de http://s.conjur.com.br/dl/relatorio-unidades-acolhimento.pdf 
Fine, A. (2001). Pluriparentalités et système de filiation dans les sociétés occidentales. In: LE GALL, D. \& Bettahar, Y. (orgs). La pluriparentalité. (p.69-93). PUF: França.

Freire, T. (2014). Cerca de 3,5 mil crianças e adolescentes acolhidos foram reintegrados à família nos primeiros seis meses do ano. Conselho Nacional de Justiça. Recuperado em 11 fevereiro de 2015, de http://www.cnj.jus.br/noticias/cnj/29464:cerca-de-35mil-criancas-e-adolescentes-acolhidos-foram-reintegrados-a-familia-nos-primeirosseis-meses-do-ano.

Fundação Oswaldo Cruz [Fiocruz] Centro Latino-Americano de Estudo de Violência e Saúde Jorge Careli; Ministério do Desenvolvimento Social [MDS]. (2010). Levantamento Nacional das Crianças e Adolescentes em Serviços de Acolhimento. Recuperado em 12 de maio 2015, de http://www.neca.org.br/images/coloquio/Levantamento_Nac_Serv_Acolhimento.pdf

Garland, D.(2008). A cultura do controle: crime e ordem social na sociedade contemporânea. Tradução de: André Nascimento. Rio de Janeiro: Revan.

Karam, M. L. (2006) .Violência de gênero: o paradoxal entusiasmo pelo rigor penal. Boletim do IBCCRIM, 14 (168), p. 6-7.

Lobo, C. (2009). Parentalidade social, fratrias e relações intergeracionais nas recomposições familiares. Sociologia, problemas e práticas, 1 (59), p.45-74.

Rifiotis, T. (2008). Judiciarização das relações sociais e estratégias de reconhecimento: repensando a "violência conjugal" e a "violência intrafamiliar". Revista Katál, Florianópolis, 11 (2), p. 225-236.

Rizzini, I.,Rizzini, I. Naif, L. \& Baptista, R. (2007). Acolhendo crianças e adolescentes: experiências de promoção do direito à convivência familiar e comunitária no Brasil.2.ed. São Paulo: Cortez; Brasília, DF: UNICEF; CIESPI; Rio de Janeiro, RJ: PUCRIO.

Rossetti-Ferreira, M. C., Almeida, I. G., Costa, N. R. A., Guimarães, L. A., Mariano, F. N. Teixeira, S. C. P. \& Serrano, S. A. (2012). Acolhimento de Crianças e Adolescentes em Situações de Abandono, Violência e Rupturas. Psicologia: Reflexão e Crítica, 25 (2), p. 390-399.

Segata, J. (2008). A "vítima" é a parte mais frágil da relação? A antropologia e a violência conjugal. 2008. Recuperado em 11 fevereiro, de 2015, de http://www.revistadireito.unidavi.edu.br/wpcontent/uploads/2010/03/DIREITOJEAN_Publicado.pdf>.

Silva, E. R. A. (Org.). (2004). 0 direito à convivência familiar e comunitária: os abrigos para crianças e adolescentes no Brasil. Brasília: IPEA/CONANDA. Recuperado em 10 de março, de 2013, de http://www.ipea. gov.br/082/08201004.jsp?ttCD_CHAVE=2386

Soares, L. C. E. C. (2013). Padrastos e madrastas: construindo seus lugares nas famílias recasadas. Tese de doutoramento não-publicada (Doutorado em Psicologia Social), Instituto de Psicologia, Universidade do Estado do Rio de Janeiro, Rio de Janeiro. 
Soares, L. C. E. C. (2015). Pais e mães recasados: vivências e desafios "no fogo cruzado"das relações familiares. 1. ed. Curitiba: Juruá.

Recebido / Received: 06/07/2015

Aprovado / Approved: 20/12/2015 